\title{
Correlation of Angiographic Findings between Right (V1 to V3) versus left (V4 to V6) Precordial ST Segment Depression in Acute Inferior Myocardial Infarction.
}

\author{
AHMED SHAFIQUL HOSSAIN ${ }^{1}$, MD. ABU SIDDIQUE ${ }^{1}$, MD. MOKHLASUR RAHMAN², MD. MUKHLESUR \\ RAHMAN ${ }^{1}$, MD. KHURSHED AHMED ${ }^{1}$, GOBINDA CHANDRA ROY ${ }^{1}$, MD. MOSTAFIZUR RAHMAN ${ }^{1}$, MD. \\ MUSTASHIRUL HAQUE ${ }^{1}$, MD. NASIMUL BARI ${ }^{1}$, AYESHA RAFIQ ${ }^{1}$, MD. SIRAJUL ISLAM ${ }^{1}$, GOLAM RAHMAN ${ }^{1}$, \\ IFTESAM RAHMAN ${ }^{2}$, SHEIK FOYEZ AHMED ${ }^{1}$, MD. ASHRAF UDDIN SULTAN ${ }^{1}$, MANZOOR MAHMOOD ${ }^{1}$ \\ ${ }^{1}$ Department of Cardiology, Bangabandhu Sheikh Mujib Medical University, Shahbag, Dhaka. ${ }^{2}$ MAG Osmani Medical College \\ and Hospital, Sylhet,
}

Address for correspondence: Ahmed Shafiqul Hossain, Department of Cardiology, Bangabandhu Sheikh Mujib Medical University, email-rumon46@yahoo.com

\begin{abstract}
The initial ECG in patients with acute inferior MI may have a great value to identify the subgroup of patients who are at high risk by predicting multivessel coronary artery disease (CAD). These patients, therefore, may benefit from a more invasive approach. ST segment depression in leads V4 to V6 but not V1 to V3 confers a greater likelihood of multivessel CAD. The aim of the study to correlate between ST-depression in ECG on admission \& severity of coronary lesion in angiogram in acute inferior MI. This study was undertaken in the department of cardiology of Bangabandhu Sheikh Mujib Medical University and in Ibrahim Cardiac Hospital \& Research Institute from March 2009 to October 2010. Patients (total 93) of acute inferior MI, who were presented within $12 \mathrm{hrs}$ of onset of symptoms and got intravenous thrombolytics were divided into three groups after initial ECG group A-without precordial ST-segment depression, group B- maximal precordial STsegment depression in leads V1-V3 and group C-maximal precordial ST-segment depression in leads V4V6.CAG was done within six weeks of MI and findings of CAG were compared among the groups. Age,sex,distribution of risk factors were identical among the groups. Significant number (53.8\%) of patients in group $C$ had a lower ejection fraction ( $L V E F<50 \%)$ than group B (30\%) and group A (10.8\%) $(p=0.001)$..Patients of group $C$ more often had double vessel disease $(38.5 \% p=0.007)$ and triple vessel disease $(30.8 \%)(p=0.014)$. In contrast, single vessel disease was more common in group $B(80 \%)(p=0.001)$.Involvement of LAD was also significantly higher in group-C (73.1\% $p=0.001)$. Left precordial ST depression (lead V4-V6) correlates with multivessel CAD, a trend toward a higher rate of $L A D$ artery disease and is associate with $L V$ dysfunction.
\end{abstract}

Key words: Inferior Myocardial Infarction, ST depression, Electrocardiogram, Coronary artery disease.

Introduction:

Anterior precordial ST-segment depression (APSTD) is common in the setting of inferior myocardial infarction (IMI). The etiology of precordial lead ST segment depression during the acute phase of an inferior myocardial infarction has been extensively investigated, with conflicting results. Three different mechanisms have been proposed for this acute electrocardiographic abnormality: 1) Concomitant anterior ischaemia (2) Reciprocal changes secondary to inferior infarction or (3) Extensive inferior or additional posterior wall infarction.

Inferior wall MI associated with reciprocal changes is a marker for increased morbidity, mortality, and complications compared to Inferor wall Myocardial infraction (IWMI) patients without reciprocal changes. When there is maximal ST-depression in leads V4-V6, there is a higher incidence of multi-vessel CAD requiring more aggressive treatment such as coronary artery bypass graft (CABG) and percutaneous coronary angioplasty (PTCA), despite apparently successful initial thrombolytic treatment. Therefore, patients with reciprocal changes should selectively receive initial management with the option to transfer to an institution with a catheterization laboratory. ${ }^{1}$

Early aggressive reperfusion therapy in this subgroup will significantly reduce the risk of major complications, inhospital death and long-term mortality and morbidity. ${ }^{2}$

Mager et $a .^{3}$ in their study found that, coronary artery bypass surgery and multivessel PCI were used in treating $65 \%$ patients of inferior wall acute myocardial infarction (AMI) with left precordial ST depression versus only 6\% of patients who did not have left precordial ST depression.

Although many of the study showed the significance of precordial ST depression in acute inferior myocardial infarction; few of them compared the different pattern of ST depression. There seems to be a major difference in the 
mechanism of left ventricular dysfunction between patients with maximum ST depression in leads V1-V3 and those with maximum ST depression in leads V4-V6.

Thus the initial electrocardiogram in patients with inferiorwall acute myocardial infarction has a great value for prediction of multivessel coronary artery disease and thereby manages these high-risk group patients with more invasive approach. Keeping this in mind, the present study was carried out to find out the relationship between different pattern of precordial ST depression and extent of coronary artery diseases.

The hypothesis of this study was "ST segment depression in leads V4 to V6 confers a greater likelihood of multivessel coronary artery disease compared to ST depression in leads V1 to V3" with the aim to correlate between STdepression in ECG on admission \& severity of coronary lesion in angiogram in acute inferior myocardial infarction.

\section{Methods:}

This cross sectional study was done in the department of Cardiology, Bangabandhu Sheikh Mujib Medical University and in Ibrahim Cardiac Hospital \& Research Institute; Dhaka from March 2009 to October 2010.The study protocol was approved by the ethical committee of BSMMU.

All patients who presented within 12 hrs of onset of symptoms, accompanied by ST elevation $0.1 \mathrm{mv}$ in $\geq 2$ inferior leads and got intravenous thrombolytics and subsequently underwent coronary angiography within six weeks of AMI was selected.

Patients are excluded if they had congenital heart disease, valvular heart disease, myocarditis, cardiomyopathy, bundle branch block, paced rhythm, ventricular rhythm, previous myocardial infarction, persistent ST depression evidenced by previous ECG record, drug effects.

Initial evaluation of the patients was done by history, clinical examination and relevant investigations. Demographic data (age, sex etc.) was recorded. Risk factor profile including hypertension, diabetes, dyslipidemia, family history of coronary artery disease and smoking was noted. Echocardiographic evaluation was done in all patients during hospital stay. In hospital complication and death was also recorded.

Patients were divided into three groups based on the pattern of precordial ST segment depression. The magnitude of ST deviation was measured $60 \mathrm{~ms}$ after the $\mathrm{J}$ point relative to TP segment.
Group A - No precordial ST depressions.

Group B - Maximum ST depression in leads $V_{1}-V_{3}$ (ST segment depression $\geq 0.1 \mathrm{mV}$ in $\geq 1$ precordial lead with

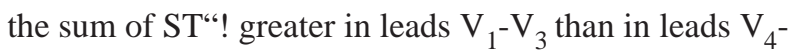
$\left.\mathrm{V}_{6}\right)$.

Group C - Maximum ST depression in leads $\mathrm{V}_{4}-\mathrm{V}_{6}(\mathrm{ST}$ segment depression $0.1 \mathrm{mV}$ in 1 precordial lead with the sum of ST depression in leads $\mathrm{V}_{4}-\mathrm{V}_{5}$ equal to or greater than the sum in leads $\mathrm{V} 1-\mathrm{V}_{3}$.

Coronary angiography was done within 6 weeks of Ml. All standard views were taken. In selected cases additional views were taken.70\% or more luminal stenosis was considered significant. The reporters of CAG had no prior knowledge of the ECG status of the patient.The report was defined as single vessel disease, double vessel disease and triple vessel disease.

After processing of all available information, statistical analysis was done by using computer based SPSS (Statistical Package for Social Science) version 12. Continuous data were expressed as mean \pm standard deviation. Categorical data were expressed as frequencies and percentage. Chi-square test and analysis of variance (ANOVA) were used as applicable. $P$ value of less than 0.05 was considered as statistically significant.

\section{Discussion:}

Out of 93 patients, 37 patients were enrolled in group A, 30 patients in group B and 26 patients in group $\mathrm{C}$.

Age distribution is almost identical in all three groups with male to female ratio was 6.8:1 (Table I).

Study of the common risk factors for coronary artery disease of the present study showed that, smoking (60.13\%) was the commonest one followed by hypertension, diabetes mellitus, dyslipidaemia and family history of CAD (Table I). Distribution of common risk factors among the groups was statistically non-significant ( $\mathrm{p}>0.05)$.

Analysis of presenting complaints showed that, the highest percentage of the patients had chest pain (88.30\%) followed by nausea or vomiting (42.46\%), sweating (28.23\%), shortness of breath (36.2\%), syncope (3\%) and epigastric discomfort (2.6\%). The presenting complaints except dizziness were almost identically distributed among the groups. Dizziness was found significantly more in group $C$ $(\mathrm{P}=0.004)$. This may be due to activation of the vagal nervous system and or ischaemia of the sinus and atrioventricular node, leading to sinus bradycardia and delays or block in the AV node and right ventricular involvement as a result of proximal RCA which was significantly more in group C. 
Table I

Basic characteristics of the study subjects $(N=93)$

\begin{tabular}{|c|c|c|c|c|c|c|c|}
\hline \multirow[t]{2}{*}{ Age (years) } & \multicolumn{2}{|c|}{ Group A(n=37) } & \multicolumn{2}{|c|}{ Group B $(n=30)$} & \multicolumn{2}{|c|}{ Group C $(n=26)$} & \multirow[t]{2}{*}{$\mathrm{p}$ value } \\
\hline & $\mathrm{n}$ & $\overline{\%}$ & $\bar{n}$ & $\overline{\%}$ & $\mathrm{n}$ & $\overline{\%}$ & \\
\hline$<30$ & 1 & 2.7 & 1 & 3.3 & 0 & 0.0 & ${ }^{\mathrm{a}} 0.662^{\mathrm{ns}}$ \\
\hline $30-39$ & 3 & 8.1 & 4 & 13.3 & 2 & 7.7 & ${ }^{\mathrm{a}} 0.712^{\mathrm{ns}}$ \\
\hline $40-49$ & 10 & 27.0 & 11 & 36.7 & 6 & 23.1 & ${ }^{\mathrm{a}} 0.504^{\mathrm{ns}}$ \\
\hline $50-59$ & 17 & 45.9 & 6 & 20.0 & 11 & 42.3 & ${ }^{\mathrm{a}} 0.069^{\mathrm{ns}}$ \\
\hline 60 and more & 6 & 16.2 & 8 & 26.7 & 7 & 26.9 & ${ }^{\mathrm{a}} 0.491^{\mathrm{ns}}$ \\
\hline Mean \pm SD & 52.2 & \pm 9.9 & 50.6 & \pm 10.4 & 52.4 & \pm 10.9 & b $0.796^{\text {ns }}$ \\
\hline \multicolumn{8}{|l|}{ Sex } \\
\hline Male & 32 & 86.5 & 27 & 90.0 & 22 & 84.6 & ${ }^{\mathrm{a}} 0.827 \mathrm{~ns}$ \\
\hline Female & 5 & 13.5 & 3 & 10.0 & 4 & 15.4 & \\
\hline \multicolumn{8}{|l|}{ Risk factors } \\
\hline Smoking & 23 & 62.2 & 17 & 56.7 & 16 & 61.5 & ${ }^{\mathrm{a}} 0.510^{\mathrm{NS}}$ \\
\hline Hypertension & 22 & 59.5 & 16 & 53.3 & 15 & 57.7 & ${ }^{\mathrm{a}} 0.672^{\mathrm{NS}}$ \\
\hline $\mathrm{DM}$ & 20 & 54.1 & 13 & 43.3 & 13 & 50.0 & ${ }^{\mathrm{a}} 0.285^{\mathrm{NS}}$ \\
\hline Dyslipidaemia & 8 & 21.6 & 7 & 23.3 & 6 & 23.1 & ${ }^{\mathrm{a}} 0.163^{\mathrm{NS}}$ \\
\hline Family history of IHD & 7 & 18.9 & 4 & 13.3 & 4 & 15.4 & ${ }^{\mathrm{a}} 0.160^{\mathrm{NS}}$ \\
\hline
\end{tabular}

$\mathrm{p}$ value reached from ${ }^{\mathrm{b}} \mathrm{ANOVA}(\mathrm{F}=0.228) /{ }^{\mathrm{a}}$ chi square test

NS $=$ not significant $(\mathrm{p}>0.05)$

$\mathrm{S}=$ significant $(\mathrm{p}<0.05)$

Group A: No precordial ST depressions

Group B: Maximum ST depression in leads $\mathrm{V}_{1}-\mathrm{V}_{3}$

Group C: Maximum ST depression in leads $V_{4}-V_{6}$

Right ventricular infarction was found common in patients with ST depression in V1-V3 which may lead to hemodynamic instability with activation of neurohumoral compensatory mechanism causing more sweating in those patients Sayami. ${ }^{4}$ In our study, although sweating (42.3\%) was significantly higher in Group-B compared to other group it was not statistically significant ( $\mathrm{p}=0.238$ ). However, we could not evaluated the incidence of RV infarction in our study because of inconsistent right sided ECG (Leads $\mathrm{V}_{3} \mathrm{R}$ and $\mathrm{V}_{4} \mathrm{R}$ ) recording. We didn't find any group having larger MI comparing with other group as evidenced by the level of troponin.

Our study clearly shows (Table II) that patient with Inferior wall AMI and precordial ST depression have a lower left ventricular ejection fraction than patient without precordial ST depression (Percentage of patients of LVEF $<50 \%$ in group A group B and group c was $10.8 \%$ vs. $30 \%$ vs. $53.8 \% \mathrm{p}=0.001$ ). Moreover, the incidence of acute LVF was more in group $\mathrm{C}$. There seems to be a major difference in the mechanism of left ventricular dysfunction between patients with group B and group C. Patients with ST depression in lead $V_{4}$ to $V_{6}$ had worse global left ventricular function than patient without precordial ST depression despite having comparable infarct size. Thus the motion abnormalities in the noninfarcted segments, or inability to induce compensatory hypercontractile response in the noninfarcted segments, are probably responsible for the worse left ventricular function of these patients ${ }^{5}$.Another explanation may be that the changes in V1-V3 is truly reciprocal and that to V4 to V6 may suggest lateral extension hence greater infarct or ischemia.

In our study, angiographic correlation (Table III) revealed that, Group C patients had significantly higher incidence of double vessel disease ( $\mathrm{p}=0.007$ for difference among the groups; $\mathrm{p}=0.009$ for the difference group $\mathrm{C}$ Vs Group A; $\mathrm{p}=0.012$ for the difference group C Vs Group B) and triple vessel disease ( $\mathrm{p}=0.014$ for difference among the groups; $\mathrm{p}=0.023$ for the difference group $\mathrm{C}$ Vs Group A; $\mathrm{p}=0.021$ for the difference group C Vs Group B).This observations were particularly remarkable which is consistent with and extend those of previous reports documenting association between lateral precordial $\left(\mathrm{V}_{4}\right.$ to $\mathrm{V}_{6}$ ) ST depression with double and triple vessel disease, where ST depression in leads $V_{4}$ to $V_{6}$, but not in leads $V_{1}$ to $\mathrm{V}_{3}$ were associated with higher rates of LAD and multivessel coronary artery disease. ${ }^{6,7}$

Regarding, single vessel disease which was found more commonly in Group B ( $\mathrm{p}=0.001$; for difference among the 
Table-II

Distribution of the patients by LVEF $(N=93)$

\begin{tabular}{|c|c|c|c|c|c|c|c|}
\hline \multirow[t]{2}{*}{$\mathrm{EF}(\%)$} & \multicolumn{2}{|c|}{ Group A $(n=37)$} & \multicolumn{2}{|c|}{ Group B $(n=30)$} & \multicolumn{2}{|c|}{ Group C $(n=26)$} & \multirow[t]{2}{*}{$\mathrm{p}$ value } \\
\hline & $\mathrm{n}$ & $\%$ & $\mathrm{n}$ & $\%$ & $\mathrm{n}$ & $\%$ & \\
\hline$<50$ & 4 & 10.8 & 9 & 30.0 & 14 & 53.8 & $0.001 \mathrm{~s}$ \\
\hline $50-60$ & 25 & 67.6 & 16 & 53.3 & 11 & 42.3 & $0.124^{\mathrm{ns}}$ \\
\hline$>60$ & 8 & 21.6 & 5 & 16.7 & 1 & 3.8 & $0.115^{\mathrm{ns}}$ \\
\hline
\end{tabular}

$\mathrm{p}$ value reached from chi square test

$\mathrm{NS}=$ not significant $(\mathrm{p}>0.05) \mathrm{S}=$ significant $(\mathrm{p}<0.05)$

Group A: No precordial ST depressions

Group B: Maximum ST depression in leads $\mathrm{V}_{1}-\mathrm{V}_{3}$

Group C: Maximum ST depression in leads $\mathrm{V}_{4}-\mathrm{V}_{6}$

Table III

Number of diseased vessels $(N=93)$

\begin{tabular}{|c|c|c|c|c|c|c|c|}
\hline \multirow{2}{*}{$\begin{array}{l}\text { Number of } \\
\text { diseased vessels }\end{array}$} & \multicolumn{2}{|c|}{ Group $A(n=37)$} & \multicolumn{2}{|c|}{ Group B $(n=30)$} & \multicolumn{2}{|c|}{ Group C $(n=26)$} & \multirow[t]{2}{*}{$\mathrm{p}$ value } \\
\hline & $\mathrm{n}$ & $\%$ & $\mathrm{n}$ & $\%$ & $\bar{n}$ & $\overline{\%}$ & \\
\hline$\overline{0}$ & 2 & 5.4 & 1 & 3.3 & 0 & 0.0 & $0.489^{\text {ns }}$ \\
\hline 1 & 28 & 75.7 & 24 & 80.0 & 8 & 30.8 & $0.001^{\mathrm{s}}$ \\
\hline 2 & 4 & 10.8 & 3 & 10.0 & 10 & 38.5 & $0.007^{\mathrm{s}}$ \\
\hline 3 & 3 & 8.1 & 2 & 6.7 & 8 & 30.8 & $0.014^{\mathrm{s}}$ \\
\hline
\end{tabular}

$\mathrm{P}$ value reached from Chi square test

NS $=$ not significant $(\mathrm{p}>0.05)$

$\mathrm{S}=$ significant $(\mathrm{p}<0.05)$

Group A: No precordial ST depressions

Group B: Maximum ST depression in leads $\mathrm{V}_{1}-\mathrm{V}_{3}$

Group C: Maximum ST depression in leads $V_{4}-V_{6}$

groups). Patients of Group C more often had AMI due to proximal RCA occlusion ( $\mathrm{p}=0.001$ for difference among the groups; $\mathrm{p}=0.275$ for the difference group $\mathrm{C} V \mathrm{~V}$ group $\mathrm{A} ; \mathrm{p}=0.001$ for the difference group $\mathrm{C}$ Vs group $\mathrm{B}$ ). However, involvement of mid RCA and distal RCA didn't differ among and between the groups. This finding was consistent with the report of Birnbaum ${ }^{5}$ et al. RCA was much more likely than the LCX in patients with acute inferior MI. Rarely, acute inferior MI may result from occlusion of the recurrent LAD branch, which is the terminal portion of a "wraparound” LAD, but this was not the case in any of our 93 patients.

This study also demonstrated that involvement of left circumflex artery was higher in Group B patients ( $p=0.028$ for the difference among the group).Involvement of proximal, distal and marginal branch of LCX didn't differ among the groups (Table IV). ST-segment depression in V1 and V2 indicates posterior injury and is typical of LCX occlusion. In this regard our study is consistent with Nair and Glancy. ${ }^{8}$

Regarding involvement of LAD, it was found that $73 \%$ patients of Group C in comparison to only $16 \%$ patients of
Group A and 10\% patient in group B ( $\mathrm{p}=0.001$ difference among the groups; $\mathrm{p}=0.001$ for the difference group $\mathrm{C}$ Vs Group A; $\mathrm{p}=0.001$ for the difference group C Vs Group B)..Mid LAD involvement was more in group-C (23.1\%) than in group-A (5.4\%) and group C (6.7\%).There were no statistically significant difference regarding involvement of proximal, distal segment of LAD and diagonal branch involvement among the groups. Some of the previous studies have suggested that ST depression in leads $\mathrm{V}_{4}$ to $\mathrm{V}_{6}$ indicates adjacent ischemia due to occlusion of a single artery (RCA or LCX).In the present study we cannot exclude this possibility. But our results as well as reports of other studies suggest that ST depression in leads $\mathrm{V}_{4}$ to $\mathrm{V}_{6}$ represents concomitant anterior ischemia due to LAD involvement.

Our results suggest that localized ST segment depression in V1-V3 is probably a reciprocal phenomenon, but ST depression in V4 to V6 is a more complex phenomenon that probably indicates some additional ischemic process unrelated to the acute occlusion of the artery, which is likely to be related to disease of the left anterior descending coronary artery and this additional ischaemic process may be severe enough to cause significant LV 
Table IV

Site of lesions in different coronary arteries $(N=93)$

\begin{tabular}{|c|c|c|c|c|c|c|c|}
\hline \multirow[t]{2}{*}{$\mathrm{EF}(\%)$} & \multicolumn{2}{|c|}{ Group A(n=37) } & \multicolumn{2}{|c|}{ Group B $(n=30)$} & \multicolumn{2}{|c|}{ Group C $(\mathrm{n}=26)$} & \multirow[t]{2}{*}{$\mathrm{p}$ value } \\
\hline & $\mathrm{n}$ & $\%$ & $\mathrm{n}$ & $\%$ & $\mathrm{n}$ & $\%$ & \\
\hline RCA & 33 & 89.2 & 19 & 63.3 & 25 & 96.2 & $0.002^{\mathrm{s}}$ \\
\hline Proximal & 18 & 48.6 & 5 & 16.7 & 17 & 65.4 & $0.001^{\mathrm{s}}$ \\
\hline Mid & 10 & 27.0 & 9 & 30.0 & 5 & 19.2 & $0.640^{\mathrm{ns}}$ \\
\hline Distal & 5 & 13.5 & 5 & 16.7 & 3 & 11.5 & $0.854^{\mathrm{ns}}$ \\
\hline LCX & 6 & 16.2 & 14 & 46.7 & 8 & 30.8 & $0.026^{\mathrm{s}}$ \\
\hline Proximal & 3 & 8.1 & 7 & 23.3 & 3 & 11.5 & $0.185^{\text {ns }}$ \\
\hline Distal & 2 & 5.4 & 5 & 16.7 & 4 & 15.4 & $0.293^{\mathrm{ns}}$ \\
\hline $\mathrm{OM}$ & 1 & 2.7 & 2 & 6.7 & 1 & 3.8 & $0.722^{\mathrm{ns}}$ \\
\hline LAD & 6 & 16.2 & 3 & 10.0 & 19 & 73.1 & $0.001^{\mathrm{s}}$ \\
\hline Proximal & 2 & 5.4 & 2 & 6.7 & 6 & 23.1 & $0.057^{\mathrm{ns}}$ \\
\hline Mid & 2 & 5.4 & 1 & 3.3 & 8 & 30.8 & $0.002^{\mathrm{s}}$ \\
\hline Distal & 1 & 2.7 & 0 & 0.0 & 2 & 7.7 & $0.260^{\mathrm{ns}}$ \\
\hline Branch & 1 & 2.7 & 0 & 0.0 & 3 & 11.5 & $0.086^{\mathrm{ns}}$ \\
\hline
\end{tabular}

$\mathrm{p}$ value reached from Chi square test

NS = not significant $(\mathrm{p}>0.05)$

$\mathrm{S}=\operatorname{significant}(\mathrm{p}<0.05)$

Group A: No precordial ST depressions

Group B: Maximum ST depression in leads $V_{1}-V_{3}$

Group C: Maximum ST depression in leads $V_{4}-V_{6}$

dysfunction. There was no normal coronary angiogram (Table III) in group C. Two patients (5.4\%) of group-A and one patient (3.3\%) of group-B were found to have no epicardial coronary artery disease. Overall, we got 2.9\% patient didn't have epicardial coronary artery disease which is consistent with Widimsky ${ }^{9}$ et al. Possible explanation for this finding probably due to coronary artery spasm, coronary artery disease in vessels too small to be visualized angiographically, and coronary artery thrombosis or embolus with subsequent clot lysis. ${ }^{10}$

\section{Conclusion:}

The presence of ST depression in lead V4 to V6 during acute inferior myocardial infarction correlates with presence of multivessel coronary artery disease comparing with maximum ST depression in leads V1 to V3 which was more commonly associated with single vessel disease.

In addition, patient with left precordial ST depression had a trend to higher rate of left anterior descending artery disease and therefore, left precordial ST depression may not be only an electrical phenomenon.

\section{Study Limitations:}

- Sample size was small.

- Right ventricular infarction was not evaluated because it was not consistently recorded and was therefore not part of the multivariable analysis.

- The higher percentage of male in the study is another limitation of the study. Involving equal ratio of both genders would have given us more representative idea.

\section{Recommendations:}

- From this study it may be recommended that the admission ECG can be used to identify subgroups of patient (ST depression in V4 to V6) with inferior AMI who have diffuse coronary disease and are at risk.

- True usefulness of this criteria need to be corroborated in larger study to develop an ECG algorithms for predicting the complexity of coronary artery lesion.

\section{Acknowledgement:}

We are grateful to Prof. M. Maksumul Haque, Consultant and Head of the Department, Ibrahim Cardiac Hospital \& Research Institute (ICH\&RI) for his kind permission, encouragement and advice to undertake this study in ICH \& RI. 


\section{References:}

1. Noelle RD, Marc L, Pollack, Theodore C. Chan, William J. Brady, Richard A. Harrigan.2004, 'Elecrocardiographic manifestation: Acute Inferior Wall Myocardial Infarction', The journal of Emergency Medicine, 26(4), 433-40.

2. Bates ER, 1997, 'Revisiting Reperfusion Therapy in Inferior Myocardial Infarction', J Am Coll Cardiol, 30, 334-42.

3. Mager A, Sclarovsky S, Herz I 2000,'Value of the initial electrocardiogram in patients with inferior-wall acute myocardial infarction for prediction of multivessel coronary artery disease', Coron Artery Dis, 11, 415-20.

4. Syami L A 2010, 'Angiographic correlation of precordial ST segment depression during acute inferior myocardial infarction',FCPS thesis,BCPS.

5. Birnbaum Y, Wagner GS, Barbash Gl, Gates K, Criger DA, Sclarovsky S 1999, 'Correlation of Angiographic Findings and Right (V1 to V3) Versus Left (V4 to V6) Precordial STSegment Depression in Inferior Wall Acute Myocardial Infarction. Am J Cardiol', 83, 143-48.

6. Hasdai D, Birnbaum Y, Porter A, Sclarovsky S 1997, 'Maximal precordial ST segment depression in leads V4-V6 in patients with inferior wall acute myocardial Infarction indicates coronary artery disease involving the left anterior descending coronary artery system', Int J Cardiol, 58, 273-78.

7. Strasberg B, Pinchas A, Barbash Gl, Hod H, Rat S, Har-Zahav Y 1990, 'Importance of reciprocal ST-segment depression in leads V5 and V6 as an indicator of disease of the left anterior descending coronary artery in acute inferior wall myocardial infarction', Br Heart J, 63, 339.

8. Nair R and Glancy DL 2002, 'ECG Discrimination between Right and Left Circumflex Coronary Arterial Occlusion in Patients with Acute Inferior Myocardial Infarction', Chest, 122, 134-39.

9. Widimsky P, Stellova B, Groch L, Aschermann M, Branny M,Zelizko M,J Stasek J, Formanek P (PRAGUE Study Group) Investigators, 2006, 'Prevalence of normal coronary angiography in the acute phase of suspected ST-elevation myocardial infarction: Experience from the PRAGUE studies', Can J Cardiol, 22(13), 1147-52.

10. Kim Mc, Kini AS and Fuster V 2008,'Definition Of Acute Coronary Syndrom', Hurst The Heart,12th edn, McGrawHill, New work,USA, 1316. 